\title{
Assessing the Microbiological Performance and Potential Cost of Boiling Drinking Water in Urban Zambia
}

\author{
Rebecca Psutka, ${ }^{+}$Rachel Peletz, ${ }^{\dagger}$ Sandford Michelo, ${ }^{\ddagger}$ Paul Kelly, ${ }^{\S}$ and Thomas Clasen ${ }^{*,+}$ \\ ${ }^{\dagger}$ London School of Hygiene and Tropical Medicine, Keppel St., London WC1E 7H, United Kingdom \\ ${ }^{\ddagger}$ Environmental Health Team, N'gombe Health Clinic, Lusaka, Zambia \\ ${ }^{\S}$ Tropical Gastroententerology and Nutrition Research Group at the University of Zambia Teaching Hospital, Lusaka, Zambia
}

Supporting Information

\begin{abstract}
Boiling is the most common method of disinfecting water in the home and the benchmark against which other point-of-use water treatment is measured. In a six-week study in peri-urban Zambia, we assessed the microbiological effectiveness and potential cost of boiling among 49 households without a water connection who reported "always" or "almost always" boiling their water before drinking it. Source and household drinking water samples were compared weekly for thermotolerant coliforms (TTC), an indicator of fecal contamination. Demographics, costs, and other information were collected through surveys and structured observations. Drinking water samples taken at the household (geometric mean $7.2 \mathrm{TTC} / 100 \mathrm{~mL}, 95 \% \mathrm{CI}, 5.4-9.7$ ) were actually worse in microbiological quality than source water (geometric mean 4.0 TTC/100 mL, 95\% CI, 3.1-5.1) $(p<0.001)$, although both are relatively low levels of contamination. Only $60 \%$ of drinking water samples were reported

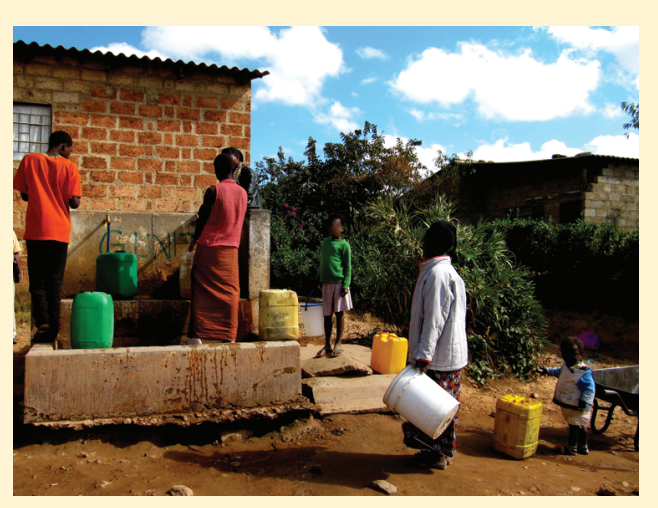
to have actually been boiled at the time of collection from the home, suggesting over-reporting and inconsistent compliance. However, these samples were of no higher microbiological quality. Evidence suggests that water quality deteriorated after boiling due to lack of residual protection and unsafe storage and handling. The potential cost of fuel or electricity for boiling was estimated at $5 \%$ and $7 \%$ of income, respectively. In this setting where microbiological water quality was relatively good at the source, safe-storage practices that minimize recontamination may be more effective in managing the risk of disease from drinking water at a fraction of the cost of boiling.
\end{abstract}

\section{INTRODUCTION}

Unsafe drinking water is a leading cause of preventable diarrheal disease, particularly among children in developing countries. Waterborne pathogens contribute to an estimated 4 billion cases and 2.5 million deaths from diarrheal disease each year. ${ }^{1}$ It is estimated that almost 900 million people lack access to improved drinking water worldwide; over 5 million of those live in Zambia. $^{2}$

In both urban and rural settings, household-based water treatment (HWT), such as chlorination, solar disinfection, and filtration, has been shown to be effective in improving water quality and reducing diarrheal disease. ${ }^{3-5}$ Studies report a protective effect from some HWT interventions even after discounting the effect estimates by the likelihood of bias and challenge of sustained use. ${ }^{6,7}$

Perhaps the oldest means of disinfecting water at the household level is boiling or heating with fuel. ${ }^{8}$ It is also the most widespread, with more than 800 million reporting that they boil their water before drinking it. ${ }^{9}$ The practice has been promoted by governments, non-governmental organizations (NGOs), and others both in developing countries where water is routinely of uncertain microbiological quality ${ }^{10}$ and in developed countries when conventional water treatment fails or water supplies are interrupted due to disasters or emergencies. ${ }^{11,12}$

Boiling presents some advantages over other means of HWT in that it is capable of killing or inactivating all classes of waterborne pathogens, including bacterial spores, protozoan cysts that have shown resistance to chemical disinfection, and viruses that are too small to be mechanically removed by microfiltration. Additionally, while chemical disinfectants and filters are challenged by turbidity and certain dissolved constituents, boiling can be used effectively across a wide range of waters. ${ }^{13}$ Perhaps most importantly, most householders already possess the tools they need to boil their water-fuel and a vessel — and thus do not rely on an uncertain supply chain and money for access to chlorine, filters, and alternative point-of-use water treatment options.

On the other hand, boiling presents certain challenges that may limit its further promotion. ${ }^{13}$ For the vast population (which may be over $50 \%$ of the world $)^{14}$ that relies on solid fuels as their

Received: February 5, 2011

Accepted: June 8, 2011

Revised: June 3, 2011 
Table 1. Demographic Characteristics of Participating Households

\begin{tabular}{|c|c|c|}
\hline & $N$ & $\%$ \\
\hline number of households & 49 & \\
\hline total population & 319 & \\
\hline number of children under 5 years of age & 64 & 20 \\
\hline household Size (mean, 95\% CI) & $6.5(5.7-7.3)$ & \\
\hline median household income/month (USD) & $\begin{array}{l}100(95 \% \mathrm{CI}, \\
96.86-120.00)\end{array}$ & \\
\hline $\begin{array}{l}\text { households living under US } \$ 1 \text { per } \\
\text { person per day }\end{array}$ & 39 & 80 \\
\hline mother's education & & \\
\hline none & 8 & 17 \\
\hline primary (grades $1-7$ ) & 24 & 50 \\
\hline secondary (grades $8-12$ ) & 15 & 31 \\
\hline \multicolumn{3}{|l|}{ father's occupation } \\
\hline no male head of household & 4 & 8 \\
\hline unemployed & 5 & 10 \\
\hline unskilled labor & 22 & 45 \\
\hline skilled labor & 12 & 25 \\
\hline administrative level & 3 & 6 \\
\hline professional & 3 & 6 \\
\hline house construction is cement & 49 & 100 \\
\hline \multicolumn{3}{|l|}{ sanitation } \\
\hline no sanitation facility & 2 & 4 \\
\hline open pit latrine & 7 & 14 \\
\hline closed (with a slab) pit latrine & 32 & 65 \\
\hline VIP latrine & 3 & 6 \\
\hline flush latrine with septic tank & 4 & 8 \\
\hline \multicolumn{3}{|l|}{ main water source } \\
\hline shallow well (unimproved) & 11 & 23 \\
\hline standpipe & 35 & 71 \\
\hline outdoor tap & 2 & 4 \\
\hline drinking vessel with narrow spout & 24 & 49 \\
\hline \multicolumn{3}{|l|}{ method of accessing drinking water } \\
\hline open pour from vessel into cup & 24 & 49 \\
\hline dip cup into vessel & 25 & 51 \\
\hline received hygiene promotion in last 6 months & 38 & 78 \\
\hline \multicolumn{3}{|l|}{ reported handwashing } \\
\hline after defecation & 48 & 98 \\
\hline before preparing food & 49 & 100 \\
\hline after child stool disposal & 47 & 96 \\
\hline after eating & 48 & 98 \\
\hline soap is present in household & 41 & 84 \\
\hline
\end{tabular}

chief source of fuel, the procurement of fuels for boiling represents a substantial commitment of cost and time, primarily for women and girls. ${ }^{15}$ Depending on the fuel used, boiling may be environmentally unsustainable and excessive fuel burning will increase greenhouse gas emissions. ${ }^{16}$ Boiling could exacerbate indoor air pollution, which contributes to respiratory disease. ${ }^{17}$ Even for those that do boil their drinking water, there is a risk of recontamination in hygiene-challenged settings because it contains no residual disinfectant and is often stored in open containers without a tap. ${ }^{19}$

This is one of a series of studies designed to assess the microbiological effectiveness and cost of boiling as a means of treating water in the home. ${ }^{13,20,21}$ To the best of our knowledge, it is the first such investigation of the use of boiling in Africa, even though the practice is the most common means of treating water on the continent. ${ }^{9}$

\section{METHODS}

Study Setting. This study was conducted over a period of six weeks (July-August 2010) in N'gombe, an urban community of 80,000-100,000 people within Lusaka, Zambia. The Lusaka Water and Sewerage Company (LWSC) provides virtually no reticulated system water into the community; neither are there government systems for sewerage, drainage, or solid waste collection. Access to water supplies is through NGO-built (and Lusaka City Council supported) standpipes delivering borehole water at two intervals each day and through some shallow hand-dug wells.

Sample Size Calculation and Enrollment of Participating Households. The primary outcome of the study was fecal contamination of drinking water measured by themotolerant coliforms (TTC), a WHO-prescribed indicator of fecal contamination. ${ }^{12}$ On the basis of previous boiling studies, it was estimated that there would be a difference of at least 10 TTC between the drinking water and the source water samples. ${ }^{13,20,21}$ Assuming a study with $80 \%$ power to demonstrate this difference at the $95 \%$ confidence-level gives a sample of 32 households, which we adjusted to approximately 50 to account for loss-to-follow-up. Prior to the commencement of fieldwork, the field investigator with the assistance of community health workers identified a convenience sample of potential study participants. Households were eligible for participation if (i) their water source was not piped into the home, (ii) the female head of household reported "always" or "almost always" boiling their water before drinking it, and (iii) they resided within the community of N'gombe.

Study details and information about confidentiality was explained to all participants in local languages and informed written consent was obtained before data collection. This study was approved by the London School of Hygiene and Tropical Medicine Ethics Committee and the Research Ethics Committee at the University of Zambia.

Participant Demographics and Reported Boiling Practices. A questionnaire was used to obtain information from the female head of each household about family demographics, household income, water source, water handling and treatment practices, hygiene practices, and sanitation facilities. The field investigator also observed and recorded details about water source, collection, transport, storage, access, and patterns of use. We used regression analysis to explore associations between these covariates and drinking water quality. In order to estimate the full economic cost of boiling, the questionnaire solicited information on how the persons responsible for boiling would otherwise spend their time on other activities.

Boiling Demonstrations. Ten households (20\%) representing the range of employment status, income, and fuel type were selected to demonstrate how they actually boil drinking water. Participants were asked to boil their water as they normally would, including the typical volume, vessel, and fuel type.

Water Sample Collection and Analysis. To evaluate the effectiveness of boiling to disinfect source water, two water samples (drinking and source) were taken from each participating household at each of five unannounced weekly visits. The households to be sampled on any given day were determined randomly using the household identification number. The "drinking 
water" sample consisted of water that the householder reported to be used for drinking at the time of the visit; immediately thereafter, a paired "source water" sample was collected from the source (standpipe, well, etc.) from which the householder reported drawing the drinking water. At the time of collecting the drinking water sample in the home, householders were asked whether that specific water had been boiled. A $125 \mathrm{~mL}$ sample was aseptically drawn directly from the household vessel or source identified by the householder into a sterile Whirl-pak bag containing sodium thiosulfate to neutralize any chlorine and was then put on ice for subsequent assessment. We assayed $100 \mathrm{~mL}$ samples for TTC using the membrane filtration method using a Del Agua and report the number of TTC for each sample in accordance with Standard Methods. ${ }^{22}$

Cost of Boiling. Because apparatus for boiling were also used in the preparation of food, their values can be considered sunkcosts. We determined the direct cost of boiling by the cost of the amount of charcoal or electricity required to heat the volume of water boiled. Indirect costs refer to the time spent boiling and will vary depending on income. Cost estimates are explained in the Supporting Information. Costs are reported using an exchange rate of 1 USD $=5000 \mathrm{ZKW}$ as per 16 August 2010 .

Data Analysis. Statistical analyses on microbiological data were performed in Excel and Stata 11. As bacterial loads followed a skewed distribution, TTC counts were transformed to their $\log _{10}$ values to achieve a normal distribution. For this purpose only, TTC counts of 0 were assigned a value of 1 . Differences in mean TTC counts of drinking and source water were assessed for statistical significance using paired Student's $t$ test. Analyses of all samples were adjusted for clustering over the five weeks. Linear regression models and ANOVA were used to explore possible associations between demographic and water handling variables and TTC levels of drinking water.

\section{RESULTS}

Participant Demographics and Characteristics. Fifty-two households were enrolled in the study, and complete data were collected from 49 (5.7\% loss-to-follow-up) (Table 1). The study population consisted of 319 individuals (mean 6.5 occupants per household), of whom $20 \%$ were children under 5 years. About two-thirds of participating female heads of household had fewer than 7 years of education. The mean monthly household income was $685,625 \mathrm{ZMK}$ (\$137 USD), mainly from wages of the male household head. Most households (71\%) accessed water from NGO-constructed standpipes connected to gravity-pressured storage tanks of borehole water, while others obtained water from shallow wells (23\%), outdoor taps from LWSC (4\%), or boreholes $(2 \%)$. Just under half of the study population stored water in containers with a narrow spout (49\%) that they used to procure their water for drinking; the balance procured their drinking water by dipping a cup into an open bucket (51\%).

Boiling Practices. All households reported that they "always" or "almost always" boil their water before drinking it, as this was a condition of eligibility for the study. Significantly, however, only $60 \%$ of drinking water samples were reported as boiled (Table 2 ). All participating households responded to an open-ended question without prompting that the purpose of boiling was to kill germs. Definitions of boiling varied from water emitting steam (39\%), bubbles on base of vessel (8\%), or full surface boil (53\%). Fuel for boiling consisted of either electricity (61\%) or charcoal (39\%) purchased from the local market, usually by the female
Table 2. Summary of boiling practices

\begin{tabular}{|c|c|c|}
\hline & $N^{a}$ & $\%$ \\
\hline \multicolumn{3}{|l|}{ recommendation/motivation of boiling } \\
\hline nobody told me & 7 & 14 \\
\hline community health worker & 33 & 67 \\
\hline mother or other relative & 6 & 12 \\
\hline church preacher & 2 & 4 \\
\hline purpose of boiling is to kill germs & 49 & 100 \\
\hline \multicolumn{3}{|l|}{ definition of "boiling" } \\
\hline steam rises from the surface & 19 & 38.8 \\
\hline tiny bubbles rise from base to surface & 4 & 8.2 \\
\hline until surface boil starts & 26 & 53.1 \\
\hline \multicolumn{3}{|l|}{ fuel data } \\
\hline \multicolumn{3}{|l|}{ fuel type } \\
\hline charcoal & 19 & 39 \\
\hline electricity & 30 & 61 \\
\hline \multicolumn{3}{|l|}{ person collecting charcoal } \\
\hline female head of household & 12 & 63 \\
\hline son or daughter & 7 & 34 \\
\hline \multicolumn{3}{|l|}{ boiling practice } \\
\hline \multicolumn{3}{|l|}{ person in charge of boiling } \\
\hline female head of household & 42 & 86 \\
\hline son or daughter & 7 & 14 \\
\hline \multicolumn{3}{|l|}{ boiling episodes per day } \\
\hline one & 24 & 49 \\
\hline two & 19 & 39 \\
\hline three or more & 6 & 12 \\
\hline mean, $95 \% \mathrm{CI}$ & $1.7(1.5-2.0)$ & \\
\hline use a lid while boiling & 48 & 98 \\
\hline volume of water boiled daily in L (median, $95 \% \mathrm{CI}$ ) & $6(5-9.7)$ & \\
\hline $\begin{array}{l}\text { time required to reach boil per } \mathrm{L} \text { in } \min \\
\text { (mean, } 95 \% \mathrm{CI} \text { ) }\end{array}$ & $5.7(3.6-7.8)$ & \\
\hline charcoal users & $5.6(3.7-7.5)$ & \\
\hline electricity users & $5.9(2.7-9.2)$ & \\
\hline taken off heat after boiling is reached & 49 & 100 \\
\hline \multicolumn{3}{|l|}{ postboiling } \\
\hline transfer water once boiled & 49 & 100 \\
\hline \multicolumn{3}{|l|}{ vessel water is transferred to } \\
\hline bucket & 19 & 39 \\
\hline jerry can or pitcher & 29 & 59 \\
\hline \multicolumn{3}{|l|}{ method of transfer } \\
\hline dip a vessel/lade for this purpose only & 2 & 4 \\
\hline dip a drinking vessel (cup) & 20 & 41 \\
\hline tilt container (open containers) & 21 & 43 \\
\hline from the spout (narrow-mouthed containers) & 6 & 12 \\
\hline mix boiled water with nonboiled water & 2 & 4 \\
\hline filter water as well as boil it & 4 & 8 \\
\hline use other methods to treat if boiling not available & 36 & 74 \\
\hline \multicolumn{3}{|l|}{ other methods used } \\
\hline chlorine/clorin & 30 & 83 \\
\hline solar disinfection (SODIS) & 6 & 17 \\
\hline
\end{tabular}

head of household (63\%). Responsibilty for boiling was normally borne by the female head of household ( $86 \%$ ), who boiled $1-2$ times daily, producing a mean volume $9.6 \mathrm{~L} /$ day. All participants 
Table 3. Geometric Mean TTC Counts per $100 \mathrm{~mL}$ in Samples of Drinking and Source Water from Study Households

\begin{tabular}{|c|c|c|c|c|c|c|c|c|}
\hline & \multirow[b]{2}{*}{$N$} & \multicolumn{2}{|c|}{ drinking } & \multicolumn{2}{|c|}{ source } & \multicolumn{2}{|c|}{ Drink:Source geometric mean ratio ${ }^{a}$} & \multirow[b]{2}{*}{ p-value } \\
\hline & & mean & $95 \%$ CI & mean & $95 \%$ CI & ratio & $95 \%$ CI & \\
\hline \multicolumn{9}{|l|}{ week 1} \\
\hline all & 52 & 4.1 & $(2.4-7.0)$ & 9.1 & $(5.0-16.7)$ & 0.5 & $(0.3-0.8)$ & $<0.01$ \\
\hline boiled on day & 33 & 2.8 & $(1.6-4.8)$ & 14.5 & $(6.83-30.6)$ & 0.2 & $(0.1-0.4)$ & 0.0001 \\
\hline \multicolumn{9}{|l|}{ week 2} \\
\hline all & 50 & 7.2 & $(3.5-14.6)$ & 5.3 & $(2.8-10.0)$ & 1.4 & $(0.73-2.5)$ & 0.33 \\
\hline boiled on day & 33 & 4.3 & $(1.9-9.8)$ & 4.4 & $(2.01-9.43)$ & 1.0 & $(0.4-2.4)$ & 0.98 \\
\hline \multicolumn{9}{|l|}{ week 3} \\
\hline all & 49 & 10.7 & $(5.1-22.3)$ & 2.4 & $(1.6-3.7)$ & 4.3 & $(1.9-9.6)$ & $<0.001$ \\
\hline boiled on day & 30 & 12.0 & $(4.3-33.6)$ & 2.4 & $(1.4-4.3)$ & 4.6 & $(1.4-14.9)$ & 0.01 \\
\hline \multicolumn{9}{|l|}{ week 4} \\
\hline all & 49 & 10.2 & $(5.1-20.3)$ & 3.4 & $(1.9-5.9)$ & 3.0 & $(1.3-6.8)$ & $<0.01$ \\
\hline boiled on day & 28 & 10.9 & $(4.2-28.5)$ & 2.6 & $(1.4-5.0)$ & 4.1 & $(1.5-11.6)$ & $<0.01$ \\
\hline \multicolumn{9}{|l|}{ week 5} \\
\hline all & 49 & 6.4 & $(3.2-12.9)$ & 2.4 & $(1.5-4.0)$ & 2.7 & $(1.5-4.8)$ & 0.001 \\
\hline boiled on day & 25 & 5.0 & $(2.0-12.6)$ & 1.7 & $(1.1-2.9)$ & 2.9 & $(1.1-7.6)$ & 0.04 \\
\hline \multicolumn{9}{|l|}{$\mathrm{all}^{b}$} \\
\hline all & 249 & 7.2 & $(5.4-9.7)$ & 4.0 & $(3.1-5.1)$ & 1.8 & $(1.3-2.5)$ & $<0.001$ \\
\hline boiled on day & 149 & 5.9 & $(4.0-8.6)$ & 4.0 & $(3.1-5.1)$ & 1.5 & $(1.0-2.3)$ & 0.08 \\
\hline
\end{tabular}

${ }^{a}$ Drink:Source geometric mean ratio indicates the difference between contamination levels observed in drinking vs source water. A contamination level $>1$ indicates that drinking water was more contaminated than source water. ${ }^{b}$ Reporting the ratios of all water samples were adjusted for clustering.

reported transferring water once boiled, a potential source of recontamination. ${ }^{24}$ Only two households reported that they mixed boiled water with nonboiled water.

Boiling Demonstrations. The boiling demonstrations showed that the amount of time spent preparing for boiling was about $2 \mathrm{~min}$ (range 1-4 min), regardless of fuel type. Women spent about $13 \mathrm{~min} / \mathrm{L}$ boiling water, during which an estimated $40 \%$ of their time could not be spent on any other activity, while the balance was engaged in other activities such as washing, cooking, or caring for their children. Women reported that the minimum amount of time they could conceive spending only on boiling was about half of what they had during the observation, roughly $20 \%$. One woman made crafts for market, while another sold juice to neighbors. These observations helped clarify the indirect cost of boiling, in terms of the time required per $\mathrm{L}$ of water boiled.

Microbiological Effectiveness of Boiling. Table 3 and Figure 1 illustrate the levels of fecal contamination that were found in drinking and source water throughout the study. Levels of contamination from the 498 water samples are organized according to $\log _{10}$ categories: $<1,1-10,11-100,101-1000$, and 1000+. Only $38 \%$ of the drinking water samples were found to be compliant with WHO recommendations of $<1$ TTC/100 mL. ${ }^{12}$ About $60 \%$ of drinking water samples fell in the "low-risk" category of 10 or fewer TTC/ $100 \mathrm{~mL}$, while $18 \%$ were in medium-risk category $(11-100)$ and over $20 \%$ of drinking water samples were classified as "high" or "very-high" risk. By comparison, more source water samples (55\%) were compliant with WHO guidelines. Seventeen percent of source water samples fell into the "low-risk" category. Contamination levels in paired water samples were positively correlated $\left.R^{2}=0.0774, p<0.001\right)$.

In this setting, the water that reported boilers were drinking (geometric mean $7.2 \mathrm{TTC} / 100 \mathrm{~mL}, 95 \% \mathrm{CI}, 5.4-9.7$ ) was actually worse in microbiological quality than their source water (geometric mean 4.0 TTC/100 mL, 95\% CI, 3.1-5.1) $(p<0.001$ )
(Table 3). Among the $60 \%$ of samples from households that reportedly boiled the water they were drinking that day, drinking water (geometric mean 5.9, 95\% CI, 4.0-8.6) was still of worse quality than source water (geometric mean 4.0, 95\% CI, 2.95.4), although the difference was not statistically significant $(p=0.08)$. Thus, even among those samples claimed to be boiled that day, the stored drinking water quality was not improved over that of the source. There was no evidence of a difference between boilers and nonboilers water quality, $p=0.17$.

We found a positive association between the number of individuals in a household and the overall geometric mean TTC in their drinking water, $R^{2}=0.105, p=0.023$. Drawing drinking water by dipping a cup into it (as opposed to pouring or using a tap) was strongly associated with an increase in drinking water contamination $(p=0.01)$, with a mean increase of 116.5 (95\% CI, 26.0-207) TTC/100 mL. We also found that those who responded that they would use alternative HWT had less contamination in their drinking water samples than those who would not use alternative HWT, $R^{2}=0.215, p=0.01$. No other covariates analyzed were associated with TTC levels in stored drinking water in the home.

Direct Cost of Boiling. The median direct cost of the $94.6 \mathrm{~g}$ of charcoal required to bring $1 \mathrm{~L}$ water to boil from $20^{\circ} \mathrm{C}$ was $145 \mathrm{ZKW}$ (0.029 USD). This was substantially less than the median direct cost of using electric stoves to bring $1 \mathrm{~L}$ water to boil from $20^{\circ} \mathrm{C}$, which was $222 \mathrm{ZKW}(0.044 \mathrm{USD})(p<0.0001)$. On the other hand, charcoal households had a median income of 500,000 ZKW (100 USD), less than electricity households' median 600,000 ZKW (120 USD). As a result, charcoal and electricity users spend similar proportions of their income on boiling drinking water, $5 \%$ and $7 \%$, respectively (Table 4 ).

Indirect Cost of Boiling. The cost of time was calculated using two values: a lower estimate using the lowest reported income of boilers in the study, and a higher estimate using the mean 
reported monthly income of boilers in the study. Both of these hourly wages are based on evidence that unskilled female laborers in Zambia work $31 \mathrm{~h}$ per week on average. ${ }^{25}$ The lowest reported wage of a boiler in the study was $927 \mathrm{ZKW} / \mathrm{h}(0.185 \mathrm{USD} / \mathrm{h})$, while the median reported wage of a boiler in the study was $3112 \mathrm{ZKW} / \mathrm{h}$ ( $0.445 \mathrm{USD} / \mathrm{h})$. More information on estimating the indirect costs of time is in the Supporting Information. Indirect costs are sensitive to the value of a woman's time and proportion of time exclusively spent boiling (Table 4).

\section{DISCUSSION}

The purpose of this study was to evaluate the microbiological effectiveness and potential cost of reported boiling as a household water treatment method as it is actually practiced in a lowresource community. Similar studies have been undertaken to investigate microbiological effectiveness ${ }^{13,20,21}$ and costs ${ }^{13,20}$

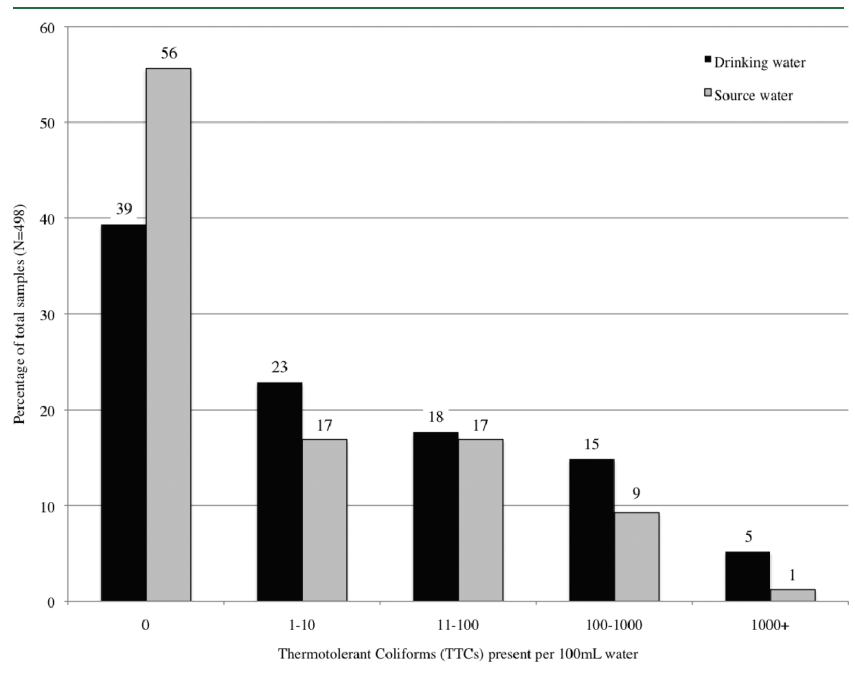

Figure 1. Percentage of drinking and source water samples $(N=498)$ by $\mathrm{WHO}$ risk category. involved in boiling water. In these locations boiling was associated with a large reduction $(86 \%-99 \%)$ in geometric mean TTCs over source water, suggesting that boiling was effective in reducing contamination. On the other hand, studies in Peru ${ }^{26}$ and Indonesia ${ }^{27}$ found that reportedly boiled water was no more likely to be free of fecal contamination than source water.

In this present case, reported boiling was not effective in improving the microbiological quality of drinking water among self-reported boilers. This was true even though the study population is estimated to be spending up to $7 \%$ of their income following this ineffective practice.

This is probably not because of noncompliance, a common problem found in studies attempting to introduce new HWT methods. ${ }^{28,29}$ Participants acknowledged that they sometimes did not boil their drinking water due to other obligations or could not boil due to frequent power outages. However, even among the $60 \%$ of the drinking water samples from householders that claimed to have been actually boiled, the level of fecal contamination was statistically equivalent to nonboilers.

Neither was the ineffectiveness of boiling likely due to improper boiling. From the boiling demonstrations in this study, only half the participants heated their water to the WHO recommended "surface boil"; the balance removed the heat source when they observed steam from the pot or bubbles forming at the bottom. However, evidence suggests that these visual signals occur at $70{ }^{\circ} \mathrm{C},{ }^{20}$ and that like pasteurization, this temperature is sufficient to kill or inactivtate most waterborne microbes. ${ }^{30}$

Our results suggest that among this study population, boiling - even if practiced consistently and correctly-may not be an optimal method of ensuring water quality in the home. This is for three reasons.

First, with only a geometric mean of $4 \mathrm{TTC} / 100 \mathrm{~mL}$, the water quality at the point of deliverly was comparatively high, limiting the potential contribution of boiling to reduce the risk of waterborne disease. Among source water samples, 55.4\% were free of fecal indicator bacteria, and another $16.9 \%$ were of low risk. Only $10.4 \%$ of samples were of high or very high risk. Previous studies

Table 4. Cost (USD) of Disinfecting 1L of Water by Boiling for Participants in the Zambian Boiling Study; median (95\% CI)

item

charcoal users, $N=19$ electricity users, $N=30$

\begin{abstract}
direct costs
median cost of fuel/L boiled

$0.029(0.01-0.037)$

$8(3.7-15.0)$

$\mathbf{0 . 0 4 4}(0.043-0.045)$

$6(5.0-10.9)$

(L): reported

median cost/month (USD)

$2.95(1.98-6.03)$

$4.8(1.7-9.1)$

$8.10(6.75-14.67)$

$6.8(5.2-12.4)$

adjusted for $60 \%$ boiling

$2.9(1.03-5.44)$

$4.06(3.11-7.44)$

indirect costs

time valued at US\$0.185/h $\mathrm{h}^{a}$

time valued at US\$0.445/ $\mathrm{h}^{b}$

time valued at $\mathrm{US} \$ 0.185 / \mathrm{h}^{a}$

time valued at US $\$ 0.445 / \mathrm{h}^{b}$

procuring fuel

preparing to boil

low boiling time: $20 \%$

high boiling time: $40 \%$

total low indirect cost ${ }^{c}$

total high indirect $\operatorname{cost}^{d}$

total maximum cost ${ }^{e}$

$0.00037(0.00017-0.00055)$

$0.00154(0.00072-0.00206)$

$\mathbf{0 . 0 0 3 0 8}(0.00223-0.00398)$

$\mathbf{0 . 0 0 6 1 7}(0.00447-0.00797)$

$0.00499(0.00312-0.00659)$

$\mathbf{0 . 0 0 8 0 8}(0.00536-0.01058)$

$0.0338(0.0238-0.0429)$

$0.00089(0.00040-0.00130)$

$0.00371(0.00174-0.00494)$

$0.0741(0.00537-0.00968)$

$\mathbf{0 . 0 1 4 8 3}(0.01074-0.01916)$

$\mathbf{0 . 0 0 7 8 7}(0.00751-0.01592)$

$0.01943(0.01288-0.02540)$

$\mathbf{0 . 0 5 4 7}(0.0375-0.0710)$

$0.00123(0.00123-0.00166)$

$0.00208(0.00154-0.00304)$

$0.00416(0.00308-0.00609)$

$0.00331(0.00277-0.00470)$

$0.00539(0.00431-0.00775)$

0.0529 (0.0474-0.0584)

$\mathbf{0 . 0 0 2 9 7}(0.00297-0.00400)$

$\mathbf{0 . 0 0 5 0 1}(0.00371-0.00732)$

$0.01001(0.00742-0.01464)$

$\mathbf{0 . 0 0 7 9 8}(0.00668-0.01132)$

$\mathbf{0 . 0 1 2 9 8}(0.01039-0.01864)$

$\mathbf{0 . 0 7 4 0}(0.0583-0.0901)$

${ }^{a} \$ 0.185 / \mathrm{h}$ is the lowest prevailing hourly wage reported by women in the study community. ${ }^{b} \$ 0.445 / \mathrm{h}$ is the median hourly wage reported by women in the study community. ${ }^{c}$ Total low indirect cost is the cost of procuring fuel + preparing to boil + low proportion of time during boiling water spent exclusively on boiling (20\%). ${ }^{d}$ Total high indirect cost is the cost of procuring fuel + preparing to boil + high proportion of time during boiling water spent exclusively on boiling $(40 \%) .{ }^{e}$ Total maximum cost to disinfect $1 \mathrm{~L}$ water by boiling is the direct cost of fuel + total high indirect cost.
\end{abstract}


of boiling have not shown the practice to yield better overall water quality than that delivered at the point of collection. ${ }^{13,20,21}$ It must be noted, however, that this five-week study may not have identified occasional degredation in source water quality that only boiling or some other means of HWT could address.

Second, the main contributor to poor drinking water quality among study households is probably recontamination, a risk that boiling alone cannot effectively mitigate. In settings where water must be stored at home due to distant and unreliable sources, there is compelling evidence that the level of fecal contamination increases in the absence of residual disinfection or safe storage. ${ }^{19}$ Because it contains no residual protection such as chlorine, boiled water is susceptible to recontamination, particularly from unclean fingers or fomites, transferring it to an unclean container after boiling, or adding other contaminated water to boiled water to accelerate cooling. The fact that water quality among the $60 \%$ of our samples drawn from households that claimed to have boiled their water was no better than that from nonboilers suggests that boiling did not consistently reduce the risk of recontamination.

Our results also suggest some possible mechanisms for posttreatment contamination of drinking water in the home. Only $49 \%$ of study households stored their drinking water in a vessel with a narrow neck (to prevent entry of hands), and 51\% reported dipping into the vessel as their nomal way to draw water for drinking. All householders transferred their water to a different container after boiling, and some filtered it through a sieve or added other water to it. In the multivariate analysis, the number of persons in the household was positiviely associated with geometric mean TTC counts. In larger households, more individuals may dip cups and hands into drinking water buckets, increasing the chance of contamination. We found that using a drinking cup to transfer freshly boiled water into the storage container was strongly associated with drinking water quality.

Third, although boiling water may have the lowest barriers to entry, continuing the practice among this population renders it more expensive than the alternatives that offer treatment plus protection against recontamination. Assuming demand for boiling and costs of fuels remain constant throughout the year, using charcoal will cost households US $\$ 4.30 /$ year and electricity will cost US\$16.20/year. This cost exceeds socially marketed sodium hypochlorite (US\$1.65/year), or solar disinfection with safe storage bottles (US\$1.92/year) for the same volume of water. ${ }^{31}$ Additionally the 3-5 year cost of boiling is more expensive than the cost of filtration options including ceramic filters that include safe storage, which cost US\$15-US\$25 and have a lifespan of at least 3 years. ${ }^{31}$ The main benefit from filters in comparison may be in time, effort, and air quality savings, which are less straightforward to financially quantify. Because water was of comparatively high quality at the source, safe storage alone may provide much of the needed protection from waterborne disease in this population for the cost of a jerry can $(15,000-40,000 \mathrm{ZMK}$ or 3-8 USD) or other narrow mouth vessel with a tap.

In this study population, the mean direct (fuel) cost of disinfecting $1 \mathrm{~L}$ of water by boiling was US $\$ 0.029$ for charcoal users and US $\$ 0.044$ for electricity users. Even excluding the economic but potentially nonmonetizable indirect (time) costs, boiling by charcoal and electricity ended up costing households $5-7 \%$ of their monthly income for those who follow the practice consistently which is necessary for it to be fully protective; the actual outlay would be $40 \%$ lower if there is only $60 \%$ compliance as was actually reported here. These figures are comparble to urban
Peru, where investigators estimated the cost of boiling to be US $\$ 0.06 / \mathrm{L}$ and the overall cost to be $7 \%$ of household income, ${ }^{26}$ lower than 1985 estimates of $10-22 \%$ in Bangladesh. ${ }^{10}$ In India, fuel costs were comparable with householders spending an estimated $6 \%$ of their income on fuel for boiling. ${ }^{20}$ In rural Vietnam, by contrast, a community relying primarily on collected wood used the economic equivalent of only $0.5-1.5 \%$ of the average monthly income for boiling. ${ }^{13}$

There are important limitations inherent in this study that limit the validity of the results. First, this study was conducted among a relatively small sample of households over a short period of time, during the dry season when levels of contamination are often lower. ${ }^{32}$ Second, study participants were not randomly selected, but were recruited by community health workers who found individuals that "always" or "almost always" boiled their water. Third, the methods used in this study did not allow the field investigator to confirm whether or not the reported boilers were actually boiling their water. The fact that only $60 \%$ of those reported "boilers" actually acknowledge having boiled the sample of drinking water that we procured from the home suggests a high level of noncompliance. While there was no evidence that such noncompliance impacted microbiological water quality in this setting, it would mitigate the protective effect in settings where the source water is more highly contaminated. Noncompliance will also reduce the potential cost of boiling that we report here. Fourth, cost estimates are based on assumptions derived from boiling demonstrations and responses to participant surveys. We also note that much of our study population used electricity for boiling, a fuel source not likely to be available to rural and othe low-income populaltions. Fifth, our constructed cost of boiling only estimates the theoretical potential cost of the practice, not the actual cost to the householders or the savings that would inure if they discontinued the practice.

Subject to these limitations, these results raise important questions about the household management of drinking water among this population in Zambia. If these results are duplicated on a wider scale, boiling would not be an appropropriate solution in this study population for improving drinking water quality. Alternative means of HWT-provided they protect against recontamination - may be a more effective, suitable, and affordable means of protecting the microbiological integrity of drinking water in this population. In fact, given that contaminated drinking water was strongly associated with using drinking cups to transfer freshly boiled water, safe storage alone may be an effective intervention among this population. While dozens of studies have assessed the health impact of household water treatment, only Roberts and colleagues have conducted an intervention trial assessing the health impact of an improved storage vessel alone, and its results were not definitive. ${ }^{33}$ This setting would seem appropriate for such a trial.

\section{ASSOCIATED CONTENT}

S Supporting Information. Details on fuel consumption and costing. This material is available free of charge via the Internet at http://pubs.acs.org.

\section{AUTHOR INFORMATION}

\section{Corresponding Author}

*Phone: (+44) 0207927 2916; fax: (+44) 0207636 7842; e-mail: thomas.clasen@lshtm.ac.uk. 


\section{ACKNOWLEDGMENT}

We thank the TROPGAN group, especially Max Katubulushi, Verah Yamayamba, Martin Simunyama, and Kelvin Saranje for their assistance and support during the fieldwork in Lusaka. Ghislaine Rosa, Laura Miller, Sophie Boisson, and Jeroen Ensink were helpful in preparation of fieldwork and assistance. We are grateful to the Environmental Health Team at N'gombe Clinic for their logistical help. This research was supported by a scholarship from the Chadwick Foundation (U.K.).

\section{REFERENCES}

(1) Kosek, M.; Bern, C.; Guerrant, R. The global burden of diarrhoeal disease, as estimated from studies published between 1992 and 2000. Bull. W. H. O. 2003, 81, 197-204.

(2) WHO/UNICEF. Joint Monitoring Programme (JMP) for Water Supply and Sanitation, 2010.

(3) Fewtrell, L.; Kaufmann, R.; Kay, D.; Enanoria, W.; Haller, L.; Colford, J. Water, sanitation, and hygiene interventions to reduce diarrhoea in less developed countries: a systematic review and metaanalysis. Lancet Infect. Dis. 2005, 5 (1), 42-52.

(4) Clasen, T.; Schmidt, W. P.; Rabie, T.; Roberts, I.; Cairncross, S. Interventions to improve water quality for preventing diarrhoea: systematic review and meta-analysis. Br. Med. J. 2007, 334 (7597), 782-785.

(5) Waddington, H.; Snilstveit, B.; White, H.; Fewtrell, L., Water, sanitation and hygiene interventions to combat childhood diarrhoea in developing countries. Synth. Rev. 2009, 1.

(6) Clasen, T.; Bartram, J.; Colford, J.; Luby, S.; Quick, R.; Sobsey, M. Comment on "Household Water Treatment in Poor Populations: Is There Enough Evidence for Scaling Up Now? Environ. Sci. Technol. 2009, 43 (14), 5542-5544.

(7) Hunter, P. Household water treatment in developing countries: Comparing different intervention types using meta-regression. Environ. Sci. Technol. 2009, 43 (23), 8991-8997.

(8) Sobsey, M. Managing Water in the Home: Accelerated Health Gains from Improved Water Supply; World Health Organization: Geneva, Switzerland, 2002

(9) Rosa, G.; Clasen, T. Estimating the scope of household water treatment in low- and medium-income countries. Am. J. Trop. Med. Hyg. 2010, 82 (2), 289-300.

(10) Gilman, R.; Skillicorn, P. Boiling of drinking-water: Can a fuelscarce community afford it? Bull. W. H. O. 1985, 63 (1), 157.

(11) Emergency Preparedness \& Response: Emergency Water Storage and Purification; US Centers for Disease Control and Prevention: Atlanta, GA, 2005.

(12) Guidelines for Drinking Water Quality; World Health Organization: Geneva, Switzerland, 2004

(13) Clasen, T.; Hoang, D.; Boisson, S.; Shipin, O. Microbiological effectiveness and cost of boiling to disinfect drinking water in rural Vietnam. Environ. Sci. Technol. 2008, 42 (12), 4255-4260.

(14) Rehfuess, E.; Mehta, S.; Prüss-Üstün, A. Assessing household solid fuel use: Multiple implications for the Millennium Development Goals. Environ. Health Perspect. 2006, 114 (3), 373.

(15) Biran, A.; Abbot, J.; Mace, R. Families and firewood: A comparative analysis of the costs and benefits of children in firewood collection and use in two rural communities in sub-Saharan Africa. Hum. Ecol. 2004, 32 (1), 1-25.

(16) Smith, K.; Uma, R.; Kishore, V.; Zhang, J.; Joshi, V.; Khalil, M. Greenhouse implications of household stoves: An analysis for India. Annu. Rev. Energy Environ. 2000, 25 (1), 741-763.

(17) Ezzati, M. Comparative Quantification of Health Risks: Global and Regional Burden of Disease Attributable to Selected Major Risk Factors; World Health Organization: Geneva, Switzerland, 2004.

(18) Smith, K. Indoor air pollution in developing countries: Recommendations for research. Indoor Air 2002, 12 (3), 198-207.

(19) Wright, J.; Gundry, S.; Conroy, R. Household drinking water in developing countries: A systematic review of microbiological contamination between source and point-of-use. Trop. Med. Int. Health 2004, 9 (1), 106-117.

(20) Clasen, T.; McLaughlin, C.; Nayaar, N.; Boisson, S.; Gupta, R.; Desai, D.; Shah, N. Microbiological effectiveness and cost of disinfecting water by boiling in semi-urban India. Am. J. Trop. Med. Hyg. 2008, 79 (3), 407-413.

(21) Rosa, G.; Miller, L.; Clasen, T. Microbiological effectiveness of disinfecting water by boiling in rural Guatemala. Am. J. Trop. Med. Hyg. 2010, 82 (3), 473-477.

(22) Eaton, A.; Franson, M. Standard Methods for the Examination of Water \& Wastewater; American Public Health Association: Washington, DC, 2005.

(23) Elliott, J.; Lira, C. Introductory Chemical Engineering Thermodynamics; Prentice Hall: Upper Saddle River, New Jersey, 1999.

(24) Lindskog, R.; Lindskog, P. Bacteriological contamination of water in rural areas: An intervention study from Malawi. J. Trop. Med. Hyg. 1988, 91 (1), 1-7.

(25) van Klaveren, M.; Tijdens, K.; Hughie-Williams, M.; Martin, N. An Overview of Womenis Work and Employment in Zambia; University of Amsterdam/ Amsterdam Institute for Advanced Labour Studies (AIAS): Amsterdam, Netherlands, 2009.

(26) Oswald, W.; Lescano, A.; Bern, C.; Calderon, M.; Cabrera, L.; Gilman, R. Fecal contamination of drinking water within peri-urban households, Lima, Peru. Am. J. Trop. Med. Hyg. 2007, 77 (4), 699.

(27) Gupta, S.; Suantio, A.; Gray, A.; Widyastuti, E.; Jain, N.; Rolos, R.; Hoekstra, R.; Quick, R. Factors associated with E. coli contamination of household drinking water among tsunami and earthquake survivors, Indonesia. Am. J. Trop. Med. Hyg. 2007, 76 (6), 1158.

(28) Arnold, B.; Arana, B.; Mausezahl, D.; Hubbard, A.; Colford, J., Jr. Evaluation of a pre-existing, 3-year household water treatment and handwashing intervention in rural Guatemala. Int. J. Epidemiol. 2009, 38,1651 .

(29) Luby, S.; Mendoza, C.; Keswick, B.; Chiller, T.; Hoekstra, R. Difficulties in bringing point-of-use water treatment to scale in rural Guatemala. Am. J. Trop. Med. Hyg. 2008, 78 (3), 382.

(30) Wegelin, M.; Canonica, S.; Mechsner, K.; Fleischmann, T.; Pesaro, F.; Metzler, A. Solar water disinfection: Scope of the process and analysis of radiation experiments. Aqua 1994, 43 (4), 154-169.

(31) Clasen, T.; Haller, L. Water Quality Interventions to Prevent Diarrhoea: Cost and Cost-Effectiveness; World Health Organization: Geneva, Switzerland, 2008.

(32) Blum, D.; Feachem, R. Measuring the impact of water supply and sanitation investments on diarrhoeal diseases: Problems of methodology. Int. J. Epidemiol. 1983, 12 (3), 357.

(33) Roberts, L.; Chartier, Y.; Chartier, O.; Malenga, G.; Toole, M.; Rodka, H. Keeping clean water clean in a Malawi refugee camp: A randomized intervention trial. Bull. W. H. O. 2001, 79, 280-287. 